\title{
Study on the Regional Green Transformation Model from Innovation Perspective
}

\author{
Chong-Mei Wang \\ Shandong Institute of Business and Technology, Yantai, China \\ worshipmei7654@163.com
}

Keywords: System innovation, Green transformation, Synergies, Complex system.

\begin{abstract}
Regional economic development in China has encountered a bottleneck of the different levels of resources and environment, along with the development of urban agglomerations, there have been some lack of coordination problems between the ecological environment and socio-economic development .International pressure from addressing climate change the ever-increasing resource and environmental constraints, the party's seventh session put forward the green transformation mode of realizing economic development through resource conservation and environmental protection. But the research is rare on complex social - economic - environmental system. Together the transition mechanism and diversified comprehensive evaluation method applied to the green transformation has just begun. The paper analyzes the collaborative mechanism of system innovation and green transformation by systematic scientific theories and synergies constructs the transformation model analyzes factors and affecting the systems analysis.
\end{abstract}

\section{Introduction}

Regional green transformation is based on protecting the environment, save energy, and improving the quality of economic growth, and realizing the sustainable development; with from black or brown economy to the green economy. Through the theory and practice of the green transformation, we think that green transformation system is a complex giant system, so as to realize the green transformation of the participation of government and the enterprise in enough, still need the public participation. That is to say, in the system, policy guarantee, under the premise of the public to the practice of the transformation system. This shows, green transformation system is an innovation system, and the system innovation is a new type of innovation system and research paradigm, the connotation is not only blending the new Schumpeter socialist, system innovation theory, also the harmonious development of the cycle theory and systematics theory [1]. German scholar, Joseph Hobo (j. Huber), advocates that the technology innovation as a driving force, the realization of the economic development of the Ecological Modernization [2]. ZhuDaJian pointed out that merely technical innovation was not enough to make the city development go on the way of sustainability, emphasizing that the city green transformation from technology innovation to ascend to the system innovation [3].

The essence of operation of the regional innovation system is complex huge system of all kinds of resources in the innovation subject distribution and use between the effective, create new innovation achievement and put into application, which affect the process of regional economy, and in the process needs to follow the control system of innovation and service, etc. various kinds of policy mechanisms. Therefore, realizing the transformation of green, the main body of the regional innovation system is including enterprise, government, industry and the public.

\section{Collaborative Mechanism Analyses}

The coordination theory tells us the system can play coordination effect by the organizer and the organized is synergy decision. Green transformation system is a typical multi-dimensional structural organization, the coordination of different dimensions is the advantage of resources sharing and integration, to complete the project or task together, otherwise, if the transformation system internal mutual undoing, discrete, conflict or friction, it will cause the entire transformation system internal 
friction, each subsystem in the system plays their due function. The whole system was in a state of disorder and confusion. Regional economic social development face resource shortage, environment pollution, population growth development bottleneck, regional economy will survive and development, in addition to collaborative internal relationship between each subsystem, but also must all the power of the coordination to improve their competitive advantage. The core of the multi-dimensional structural organization coordination process is different between dimensions collaborative platform, as an open system, multi-dimensional structural organization is through the external collaborative platform for environmental information, carries on the strategic analysis, found that collaborative opportunities. Multi-dimensional structural organization of collaborative mechanism by below figure 1 can be shown.

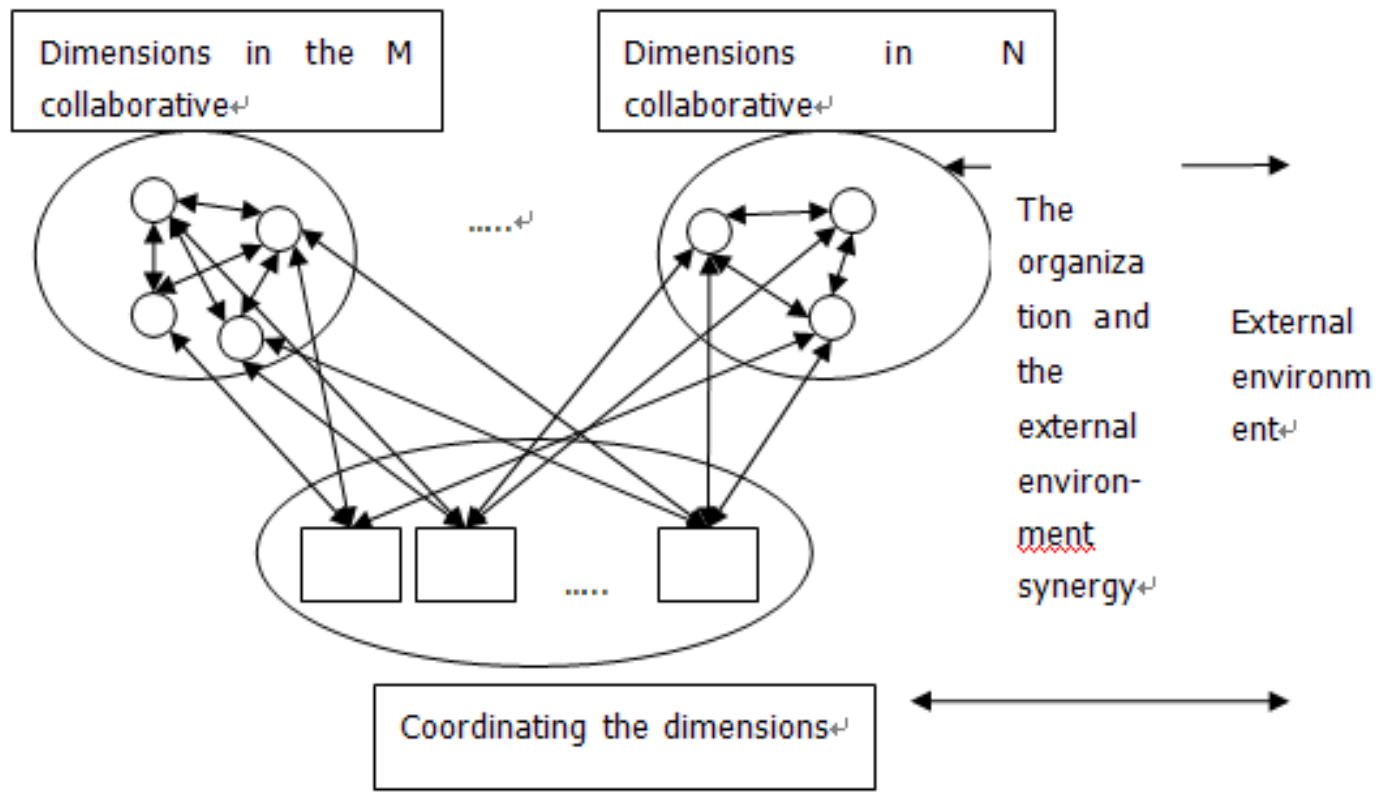

Fig. 1 multidimensional structure with the mechanism model

\section{The Mutual Interaction of the System Innovation and Transformation}

From the point of view of a modern system science, collaboration is refers to the various components of the internal system between the harmonious state, that is, far from the balance state in the open systems conditions, between components order parameter and the interaction between the, make the system from disorder chaos state into macro order self-organization process. The organization of the system is the system process of interaction between the components .Therefore, the system of the organizational process must be a dynamic process.

From the theory and current situation of green transformation analysis, we can see that the system innovation angle is lack of green transformation research, so it can't form the transition of the theoretical support and guiding the practice. This paper studied the system innovation choice as the internal the organization system, the external environment as an external organization system with the main body of the system as the organization system on the synergy relationship. Therefore, this paper emphatically analyzed the relationships between internal components and the relationships Based on the research of the system innovation of green transformation, be the first to demonstrate a link exists between close cooperative relationship, accordingly, this section from several different angles mainly describes system innovation and transformation of the collaborative relationship between green. Figure 2 showing a link between one of mutual interaction analysis.

(1) The innovation and transformation of the synergy goal lies in the multi-level and diversified, the multidimensional produces different levels and the direction of correlation effect and synergy effect, causing system whole orderly evolution, can for the performance for the area the strength of the ascension and sustainable development.(2) The innovation and transformation synergy includes 
internal and external causes .Internal power is free of major area of non-renewable resources dependence, overcoming the crisis seeking for the sustainable development intrinsic demand. External power mainly is the macro environment of the formation of the pulling power. (3) The main body of the innovation and transformation is including enterprise, government, industry and the public. And by the innovation resources transmission, it realized the innovation of the energy supplement, promoting innovation behavior. (4) The innovation function and transformation process work with system innovation to make different innovation function synergistic effects, get greater than the sum of the total effect innovation function. (5) The innovation ability and the ability of the transition work with system innovation ability and regional green transformation ability has the correlation, and when they both fall in the high correlation relationship is, within the scope of the system innovation ability and green transformation ability is at the coordination state. .

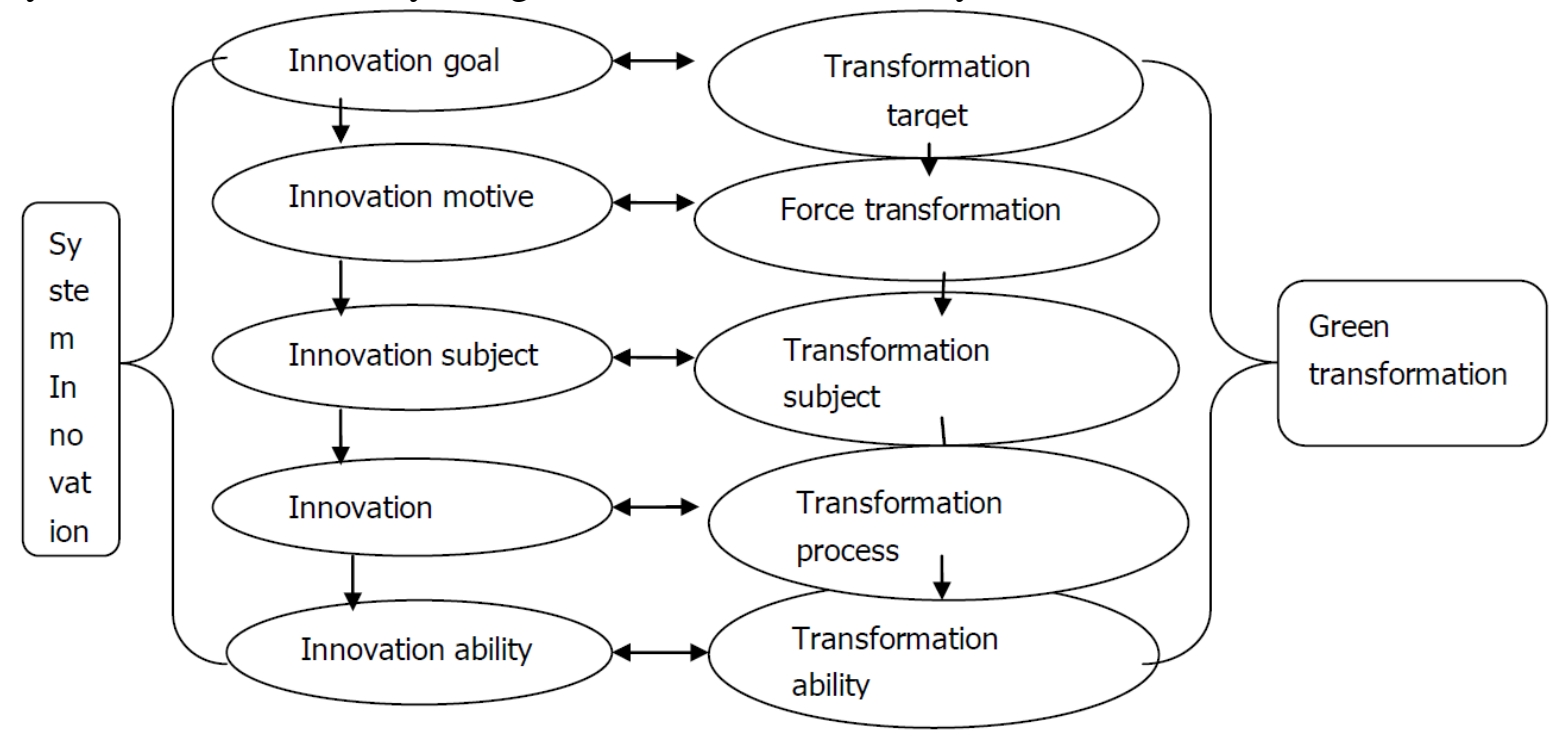

Fig. 2 system innovation and transformation of the mutual interaction should be green relationship

\section{The Construction of the Model}

Many factors affect the green transformation system innovation way of green transformation process, which is also the recognition of the transformation of order parameter, through the different elements of the optimal integration innovation, system innovation of the expansion of produce effect, thus build up a broader green transition platform and a more harmonious green transformation mechanism, building a more perfect green environmental transformation, providing a more reasonable green transformation regulation. System innovation makes different innovation function synergistic effects greater than the sum of the total effect innovation function. From the innovation development and economic growth's practice, the innovation of systemic influence function, more depends on factors such as the system, policy and related network system linkage effect.

The external force of system transformation is the answer of force system regional why to want to make green the problem of transition? In the green transformation in complex system, economy, population, resource, environment four subsystems interaction and mutual influence, mainly in production, circulation and consumption of material products in the process, it includes four parts: from the resources development to processed into products to consumption, and finally become waste disposal to external environment.

With the rapid development of society, the humanity will certainly face resources exhausted and gradually destroys the environment, leading to economic and social development and the resource environmental contradiction to upgrade. This contradiction impacts the human sustainable economic and social development [5].

Subject system transformation by the enterprise, government and industry and the public, which is the transformation of green can be made by the way of system operation in this paper. The system 
is the answer to the implementation of the green area who by the problem of transition. Green transformation is the subject of diversified, mainly including the enterprise and the public, industry and government. The public life, from consumption idea and behavior in the analysis, the public life, consumption habits and preferences will affect the enterprise production behavior, it is green in the process of transformation based; Enterprise implement green transformation is mainly from micro begin, as green transformation in main body core Yuan; The green industry transformation of the medium level from the start, it is a core subject in the process of transformation of the green, green transformation to play a supporting role framework; The government implement green transformation from the macroscopic level began, it's green smooth transition of effective guarantee. In this process, all kinds of will and behaviors can form green transformation of the resultant force.

It is concluded that in the transformation system innovation of green area, the enterprise and government are the main subject. To achieve innovation, local government security is evitable to good innovation environment, including policy and infrastructure and so on. But, just it relies on enterprises; the local government is still not enough, the public participation consciousness, participation enthusiasm play one very important role.

\section{Acknowledgements}

Shandong collaborative innovation center of energy economy (2014 SDXT011)

\section{References}

[1] Cooke P, Hans-Joachim Bracey HJ and Heidenreich M. (Eds.). Regional Innovation Systems: the Role of Governance in the Globalized World [M].London: UCL Press, 1996:102-108.

[2] Joseph Huber. Towards Industrial Ecology: Sustainable Development as a Concept of Ecological Modernization [EB/OL]. (1998-9-10) [2007-10-28].

http://www.soziologie.uni-halle.de/huber/docs/towards.pdf.

[3] Zhu Dajian. Based on the method of China's urban green PSR transition study [J]. Journal of tongji university (social sciences), 2011,08:37.

[4] Zhao Kun. Based on the system innovation of industry transformation of resources city and the applied research [D]. Tai "an: Shandong science and technology university Ph.D. Thesis, 2009:12-13.

[5] Zhang Chen. China resources city green composite system transformation in taiyuan, Shanxi Province practice research-inspired [D]. Tianjin: nankai university Ph.D. Thesis, 2010:173. 